\title{
Phenolic compounds and aroma-impact odorants in herb liqueurs elaborated by maceration of aromatic and medicinal plants in grape marc distillates
}

\author{
Raquel Rodríguez-Solana, ${ }^{1,2}$ José Manuel Salgado, ${ }^{3}$ \\ José Manuel Domínguez ${ }^{1,2}$ and Sandra Cortés-Diéguez ${ }^{1,2 *}$
}

\begin{abstract}
Twenty-eight commercial herb liqueurs, elaborated by maceration of aromatic and medicinal plants in grape marc distillate, were analysed. Thirty-two volatile compounds were identified and quantified by gas chromatography-mass spectrometry, whereas seven phenols were determined by high-performance liquid chromatography with UV detection. All compounds showed significant differences among the samples analysed as consequence of the initial composition of the distillate and the plants and spices used in the liqueur elaboration. Of the 32 volatile compounds identified, 18 were considered to be impact odorants (odour activity value $\geq 1$ ) and these were classified into six odorant series. Spice, fruity and floral were the series that contributed the most to the aroma profile of the evaluated liqueurs. A first principal components analysis (PCA) was performed on the concentration of the seven phenols and these accounted for $75.37 \%$ of the total variance and a second PCA was performed on the concentration of the 18 impact odorants and these accounted for $60.96 \%$ of the total variance; allowing for the classification of the liqueur samples into three different groups. Copyright $\odot 2016$ The Institute of Brewing \& Distilling
\end{abstract}

Keywords: aromatic series; herb liqueurs; impact odorants; odour activity values; phenolic compounds

\section{Introduction}

Analytical composition and sensory qualities of distilled beverages depend on the raw material, the storage and fermentation conditions and the distillation process (1-6). Orujo is an alcoholic beverage that is highly popular in Galicia (NW of Spain) with similar analytical characteristics to Bagaçeiras (Portugal), Grappa (Italy), Tsipouro (Greece) and Marc (France) (7-9). These alcoholic beverages are obtained by distillation of the solid residues of grapes (stems, seeds and skins) after alcoholic fermentation. An important number of volatile compounds belonging to different chemical families (ethyl esters, acetates, aldehydes, alcohols, acids and terpenes) have been identified by gas gas chromatography-mass spectrometry and correlated with the corresponding sensorial attributes (10).

Besides the non-aged distillate, many alcoholic beverages are aromatized with essential oils of plants, spices and fruits, after maceration or after a new distillation process. During these stages, the ethanol of the distillate extracts specific components with aromatic and antioxidant properties, changing the analytical and sensory profile of the initial drink.

Traditionally Orujo is macerated with various aromatic plants to elaborate herb liqueurs. Since 2004, the elaboration conditions and the analytical composition and sensory quality of these beverages are also regulated (11). This normative establishes that the elaboration process includes the use of at least three aromatic and medicinal plants (AMP), the more recommended being mint (Mentha piperita L.), aloysia (Aloysia triphylla), oregano (Origanum vulgare), coriander (Coriandrum sativum L.), fennel (Foeniculum vulgare), nutmeg (Myristica fragrans), chamomile (Matricaria recutita L.), rosemary (Rosmarinus officinalis L.), thyme (Thymus vulgaris L.), orange blossom (Citrus sinensis), licorice (Glycyrrhiza glabra L.) and cinnamon (Cinnamomum verum).

The number and proportion of each plant depend on the unique recipe of the producing company, which usually keeps it a secret. The elaboration of this kind of alcoholic beverages has a long tradition in this part of Spain. Herbal liqueurs made with Orujo are well known and appreciated worldwide, mainly by their digestive properties. However, compared with the large number of published references about the analytical and sensory characteristics of young distillates, the herbal liqueurs have had few studies reported.

In this paper the first results available on the analytical profile (aroma and phenol compounds) of this kind of alcoholic beverages are presented, with the goal of providing general information about the mean composition of the traditional herbal liqueurs elaborated in Galicia. This work was demanded by the corresponding Regulating Council to characterize these kinds of beverages

\footnotetext{
* Correspondence to: S. Cortés-Diéguez, Laboratory of Agro-food Biotechnology, CITI-Tecnópole, Parque Tecnológico de Galicia, San Cibrao das Viñas, Ourense, Spain. E-mail: smcortes@uvigo.es

1 Department of Chemical Engineering, Sciences Faculty, University of Vigo (Campus Ourense), As Lagoas s/n32004, Ourense, Spain

2 Laboratory of Agro-food Biotechnology, CITI-Tecnópole, Parque Tecnológico de Galicia, San Cibrao das Viñas, Ourense, Spain

${ }^{3}$ CEB-Centre of Biological Engineering, University of Minho, Campus de Gualtar4710-057, Braga, Portugal
} 
and to compare them with those liqueurs that have been elaborated with artificial aromas or extracts, two forbidden practices, in order to detect frauds and infractions. Currently work is also ongoing on the individual characterization of the liqueurs to determine the capacity of ethanol to extract essential oils from each plant.

\section{Materials and methods}

Samples of herbal liqueurs were analysed by GC and highperformance liquid chromatography (HPLC) to identify the volatile and phenolic compounds in order to characterize them and to distinguish them from other similar alcoholic beverages.

\section{Liqueur samples}

A total of 28 samples of commercial herb liqueurs from different companies, belonging to the Geographic Denomination 'Spirits and Traditional Liqueurs from Galicia', were subjected to analysis. All of them were elaborated according with the Geographic Denomination rules and their composition and sensory characteristics were also controlled, so their origin and authenticity could be guaranteed. Herb liqueur elaboration includes a first stage of maceration of several medicinal plants and species (a minimum of three) in grape marc distillate. The type and number of aromatic plants employed in the maceration depends on the process of the particular elaboration. After a minimum maceration process (a period of time fixed by the company), the macerate is diluted and sweetened with sugar or caramel and filtered before bottling.

\section{Reagents and standards}

The chemical standards used were as follows: linalool, $\alpha$-terpineol, citronellol, nerol, geraniol, benzaldehyde, menthol, eugenol, isoeugenol, guaiacol, 1,8-cineol, $\alpha$-pinene, 2-phenyl ethanol, 5hydroxymethyl furfural, 4-hydroxy-3-methoxybenzyl alcohol (vanillyl alcohol), 4-hydroxy-3-methoxybenzoic acid (vanillic acid), 4-hydroxy-3-methoxyacetophenone (acetovanillone) and benzoic acid, all supplied by Sigma-Aldrich (Switzerland). The compounds 3-octanol, benzyl alcohol, phenyl-ethyl acetate, $\alpha$-ionone, $\beta$ ionone, $\beta$-damascenone, 2 -furancarboxaldehyde (furfural) and 4hydroxy-3-methoxybenzaldehyde (vanillin) were purchased from Fluka (Switzerland). Limonene, ethyl butyrate, thymol, trans-anetol and $\gamma$-undecanolactone were supplied by Acros Organics, Fisher Scientific (Madrid, Spain). Isoamyl acetate sourced was from Panreac (Barcelona, Spain). Absolute ethanol, ether and hexane, used as solvents, were purchased from Merck (Darmstadt, Germany). Methanol (HPLC-gradient grade) and formic acid were supplied by Panreac (Barcelona, Spain) and the Milli-Q water was from a Millipore system (Bedford, MA).

\section{Extraction of volatiles}

One millilitre of internal standard (3-octanol, $48 \mathrm{mg} \mathrm{L}^{-1}$ ) and a magnetic stir bar were added to $30 \mathrm{~mL}$ of sample (herb liqueur) or standard and placed into a conical Erlenmeyer flask with a stopper. All samples were previously diluted with $20 \mathrm{~mL}$ of distilled water in order to reduce the alcohol content and improve the extraction process. Each sample/standard was extracted with diethyl ether-hexane (1:1) three times (4, 2 and $2 \mathrm{~mL}$, respectively), at $300 \mathrm{rpm}$ for $5 \mathrm{~min}$. In each extraction, after $5 \mathrm{~min}$ at room temperature in a separatory funnel, the organic phase was separated from the aqueous layer. The three consecutive diethyl etherhexane extracts were transferred, without concentration, into a screw-cup vial and subjected to gas chromatography analysis.

Stock standard solutions of each volatile compounds were prepared by dissolving the pure standard in ethanol. Working standard solutions of each compound were prepared daily by mixing an aliquot of each individual solution and diluting with ultrapure water to obtain a final ethanol content of $10 \%(\mathrm{v} / \mathrm{v})$. The internal standard for GC analysis, 3-octanol, was prepared in absolute ethanol $100 \% \quad(\mathrm{v} / \mathrm{v})$. Extractions of volatiles from each sample/standard were made in triplicate.

\section{GC-FID and GC-MS analysis}

Volatile compounds were analysed in an Agilent 7890 A gas chromatograph equipped with an Flame Ionization Detector (FID) system (Agilent Technologies, Deutschland, Germany) for quantification purposes. The organic extract $(2 \mu \mathrm{L})$ of each sample was injected directly into the chromatograph. The capillary column used was a Zebron ZB-WAX $(60 \mathrm{~m} \times 0.25 \mathrm{~mm}$ i.d., film thickness $0.25 \mu \mathrm{m}$ ) from Phenomenex (Torrance, CA, USA).

The gas chromatographic operation conditions were as follows: injector temperature, $250^{\circ} \mathrm{C}$; detector temperature, $260^{\circ} \mathrm{C}$; carrier

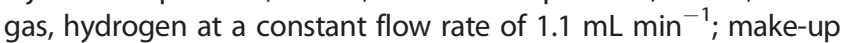

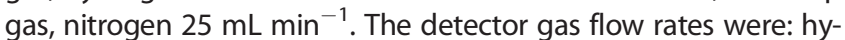

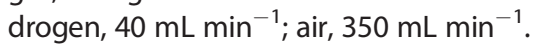

The oven temperature programme was $5 \mathrm{~min}$ at $60^{\circ} \mathrm{C}$, then $1.5^{\circ}$ $\mathrm{C} \min ^{-1}$ to $80^{\circ} \mathrm{C}$ and finally to $225^{\circ} \mathrm{C}$ at a rate of $3^{\circ} \mathrm{C} \min ^{-1}$. The injection was made in split mode (1:5).

The extract was also analysed by GC-MS for identification purpose of the volatile compounds. The GC was a Finningan Trace DSQ (Thermo, Austin, USA). The column was a HP Innowax $(60 \mathrm{~m} \times 0.25 \mathrm{~mm}$ i.d., film thickness $0.25 \mu \mathrm{m})$ from Agilent (Agilent Technologies, Deutschland, Germany). The carrier gas was hydro-

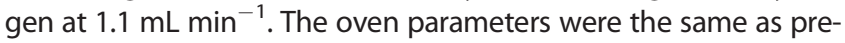
viously described for GC-FID analyses. Mass spectra were acquired in the electron impact mode (ionization energy, $70 \mathrm{eV}$, source temperature $200^{\circ} \mathrm{C}$ ) at $5 \mathrm{scan} \mathrm{s}^{-1}$, using full scan with a mass acquisition from $\mathrm{m} / \mathrm{z} 10$ to 1000 .

The identification of most of the volatile compounds was achieved by comparison of retention times and mass spectra with those of pure standard compounds. Identification was considered tentative when it was only based on the match mass spectra of the compound with the reference mass spectra of the NIST library.

Quantitative analyses were made employing the corresponding response factor for each compound in the reference solution, according to the internal standard method using the chromatograms obtained in the GC-FID analysis.

\section{HPLC analysis}

All samples of liqueurs were filtered through $0.22 \mu \mathrm{m}$ pore membranes (Sartorius, Goettingen Germany) before the analysis in order to determine, by HPLC, some cinnamic acids, phenolic and furanic aldehydes and their derivates. An Agilent Technologies 1200 series system consisting of a quaternary pump (G1311 A), an injector (5 $\mu \mathrm{L}$ injection loop), a degasser (G1322 A), a UV detector (Agilent, Palo Alto, CA) and a Zorbax SB-Aq reverse-phase column (Agilent, Palo Alto, CA) with a guard column were employed. Separation was achieved using a linear gradient run at $35^{\circ} \mathrm{C}$ in $65 \mathrm{~min}$ from 0 to $48 \%$ of $A$ at a flow rate of $1 \mathrm{~mL} \mathrm{~min}{ }^{-1}$ consisting of two solvents: solvent $\mathrm{A}(100 \%$ methanol) and solvent 
B (2.5\% formic acid in Milli-Q water, v/v). Detection was carried out at $276 \mathrm{~nm}$.

The identification of each compound was performed by comparing retention times with those of pure standards. Quantification was done by external calibration preparing calibration curves of six points with concentrations of: vanillin, $0.5-12 \mathrm{mg} \mathrm{L}^{-1}$; vanillic acid, 0.3-10 $\mathrm{mg} \mathrm{L}^{-1}$; vanillyl alcohol, $0.1-4 \mathrm{mg} \mathrm{L}^{-1}$; benzoic acid, 0.5$45 \mathrm{mg} \mathrm{L}^{-1}$; acetovanillone, $0.1-10 \mathrm{mg} \mathrm{L}^{-1}$; furfural, $0.1-10 \mathrm{mg} \mathrm{L}^{-1}$; and 5-hydroxymethylfurfural (HMF), $0.1-100 \mathrm{mg} \mathrm{L}^{-1}$. Coefficient of determination $\left(R^{2}\right)$ was 0.9935-0.9999.

Stock standard solutions for HPLC analysis were prepared in ultrapure water with $1 \%(\mathrm{v} / \mathrm{v})$ of absolute ethanol. All determinations were performed in triplicate.

\section{Odour activity values}

The odour activity value (OAV) is defined as the ratio between the concentration of a volatile compound in a sample and its odour perception threshold value. Volatile compounds with $\mathrm{OAV} \geq 1$ are considered to contribute directly and individually to the aroma and they are commonly appointed as the most important volatile compounds or the most active odorants. The rest of volatiles with OAV $<1$, could increase the aromatic notes of other compounds through synergistic effects and therefore contribute to the global aroma. To evaluate the contribution of each volatile compound to herbal liqueurs aroma, the OAV were calculated.

\section{Statistical procedures}

All instrumental data obtained were analysed using XLstat-Pro (Addinsoft). One-way Analysis of Variance (ANOVA) was applied to establish whether significant differences $(p<0.05)$ existed between the values obtained for the mean concentration of each compound in the different herbal liqueurs analysed. The multiple range test (LSD) was applied to confirm the results obtained. Principal component analysis (PCA) on phenol compounds and impact odorants (OAV $\geq 1)$ was also applied.

\section{Results and discussion}

The major commercial brands of herb liqueurs from Galicia (Spain) were analysed in this study in order to determine the most abundant phenolic compounds and impact odorants that can describe them.

\section{Phenolic composition}

Phenolic compounds in herb liqueurs may come from the grape marc distillate or the plants used in their elaboration process. Winery by-products, before and after distillation contain a large amount of phenolic compounds with antioxidant activity and several positive effects on human health $(12,13)$. The maceration of the plants in the distillate increases the phenolic content and the corresponding health benefits.

In total, seven phenolic compounds were identified by HPLC in the 28 liqueur samples analysed. All samples showed similarities in the qualitative phenolic profile, but differed significantly $(p \leq 0.05)$ from a quantitative point of view (Table 1). The compounds HMF and benzoic acid were the phenols with higher concentrations, whereas vanillyl alcohol, vanillin and acetovanillone were those with the lower content.

The last three compounds (lignin-derived compounds) are more related to wood-aging (14), but they are also present in several aromatic and medicinal plants and then in the corresponding liqueur. Vanillic acid was detected in F. vulgare Mill. (15) and in a lower quantity in extracts from rosemary (16). Štěrbová et al. (17) also identified vanillic and benzoic acid in extracts obtained from T. vulgaris $\mathrm{L}$.

Phenolic acids, vanillic and benzoic, are secondary metabolites, implicated in allelopathy in plants (17). These compounds are potentially protective factors against cancer and heart diseases owing to their potent antioxidative properties and their presence in a wide range of commonly consumed foods of plant origin (18). Vanillin as natural flavouring also could be added to increase the global aroma of the liqueur (11).

Furfural and HMF are formed from pentose and hexose dehydration, respectively, along the distillation or storage process. However, their concentration in the herb liqueur also depends on the quantity of caramel colours added as colouring and sweetener. This could justify the higher concentration of HMF in some of the samples analysed.

\section{Volatile compounds}

Methanol, ethyl acetate, acetaldehyde and the total content of a group of higher alcohols (2-butanol, 1-propanol, 2-methylpropanol, 1-butanol, 2-methyl-butanol and 3-methyl-butanol) are the more abundant volatile compounds in grape marc distillate and thus in the corresponding liqueurs. Their presence and concentration are controlled by the Regulating Council, which fixes minimum and maximum values for them. All samples analysed were commercial herb liqueurs previously certified by the

Table 1. Phenolic composition ( $\mathrm{mg} \mathrm{L}^{-1}$ ) of the herb liqueurs

\begin{tabular}{|c|c|c|c|c|}
\hline Compound & Minimum & Maximun & Mean \pm SD & Significance \\
\hline 4-Hydroxy-3-methoxybenzyl alcohol (vanillyl alcohol) & Trace & 2.69 & $0.28 \pm 0.54$ & * \\
\hline Benzoic acid & 0.87 & 11.41 & $2.77 \pm 2.11$ & * \\
\hline 4-Hydroxy-3-methoxybenzoic acid (vanillic acid) & Trace & 9.72 & $1.33 \pm 2.30$ & * \\
\hline 4-Hydroxy-3-methoxybenzaldehyde (vanillin) & Trace & 3.89 & $0.76 \pm 1.16$ & * \\
\hline Acetovanillone & Trace & 8.41 & $0.89 \pm 1.88$ & * \\
\hline 2-Furancarboxaldehyde (furfural) & 0.83 & 4.84 & $2.19 \pm 1.04$ & * \\
\hline 5-Hydroxymethylfurfural & Trace & 37.28 & $3.55 \pm 7.58$ & * \\
\hline
\end{tabular}


Geographic Denomination and, for this reason, we did not included these major volatile compounds in the 'Results and Discussion' of this manuscript, because their content did not show significant differences and did not contribute to the characterization of these kind of alcoholic beverages.

Thirty-two volatile compounds, belonging to six different chemical families (terpenes, alcohols, carbonyl compounds, $\mathrm{C}_{13}$ norisoprenoids, volatile phenols and lactones) were identified in the herb liqueurs analysed (Table 2). Mean values, standard deviations and ranges (minimum and maximum) are shown.

Table 2 reveals that all volatile compounds identified in the herb liqueurs, except isoeugenol, showed significant differences for the mean concentration. Ten compounds showed standard deviation higher than their mean value, indicating a broad range for the analysed samples. This is due to the different mix of aromatic and medicinal plants used by companies during the maceration process. The most abundant volatile was 2phenyl ethanol (73.45\%). This compound can originate from both the distillate and the plants used in the elaboration of liqueurs.

Results in Table 2 show that the total amount of terpenes in the herb liqueur composition was also significant. Linalool (2.16\%) is a terpene compound present in the majority of grape marc distillates obtained from the main aromatic white grape varieties of Vitis grown in Galicia (NW of Spain). This compound is present in distillates in a concentration range of $0.01-7.87 \mathrm{mg} \mathrm{L}^{-1}$ (19); however, the high concentrations of linalool in some of the herb liqueurs analysed must be consequence of the maceration of different plants. Linalool is the main compound founded in coriander (20) and orange blossom (21). Lower concentrations of linalool also

Table 2. Volatile composition of the herb liqueurs $\left(\mathrm{mg} \mathrm{L}^{-1}\right)$

\begin{tabular}{|c|c|c|c|c|}
\hline Compound & Minimum & Maximun & Mean \pm SD & Significance \\
\hline \multicolumn{5}{|l|}{ Terpenes } \\
\hline Linalool & 0.36 & 10.33 & $1.68 \pm 2.91$ & * \\
\hline$\alpha$-Terpineol & 0.15 & 0.54 & $0.28 \pm 0.12$ & * \\
\hline Citronellol & 0.03 & 0.17 & $0.10 \pm 0.04$ & * \\
\hline Nerol & 0.05 & 0.17 & $0.09 \pm 0.05$ & * \\
\hline Geraniol & 0.02 & 0.08 & $0.03 \pm 0.02$ & * \\
\hline Menthol & 0.02 & 5.69 & $1.68 \pm 2.40$ & * \\
\hline$\alpha$-Pinene & $<$ L.Q. & 0.07 & $0.03 \pm 0.02$ & * \\
\hline Limonene & 0.01 & 0.32 & $0.05 \pm 0.09$ & * \\
\hline 1,8-Cineole & 0.03 & 0.28 & $0.15 \pm 0.10$ & * \\
\hline Thymol & 0.03 & 0.95 & $0.24 \pm 0.34$ & * \\
\hline Citral & 0.05 & 5.22 & $0.57 \pm 1.55$ & * \\
\hline \multicolumn{5}{|l|}{ Alcohols } \\
\hline Benzyl alcohol & 0.09 & 0.46 & $0.24 \pm 0.12$ & * \\
\hline 2-Phenyl ethanol & 11.58 & 124.01 & $57.10 \pm 37.68$ & * \\
\hline \multicolumn{5}{|l|}{ Carbonyl compounds } \\
\hline Benzaldehyde & 0.44 & 0.98 & $0.61 \pm 0.19$ & * \\
\hline \multicolumn{5}{|l|}{$C_{13}$-Norisoprenoids } \\
\hline$\alpha$-lonone & $<$ L.Q. & 0.02 & $0.01 \pm 0.00$ & * \\
\hline$\beta$-Ionone & 0.01 & 0.02 & $0.02 \pm 0.03$ & * \\
\hline$\beta$-Damascenone & 0.01 & 0.05 & $0.02 \pm 0.02$ & * \\
\hline \multicolumn{5}{|l|}{ Acetates and ethyl esters } \\
\hline Isoamyl acetate & 0.13 & 0.91 & $0.62 \pm 0.22$ & * \\
\hline Hexyl acetate & 0.27 & 1.99 & $1.02 \pm 0.46$ & * \\
\hline Phenyl ethyl acetate & 0.02 & 0.19 & $0.07 \pm 0.05$ & * \\
\hline Ethyl propionate & 0.15 & 0.86 & $0.33 \pm 0.18$ & * \\
\hline Ethyl butyrate & 1.20 & 3.32 & $1.94 \pm 0.66$ & * \\
\hline Ethyl hexanoate & 0.04 & 0.13 & $0.08 \pm 0.05$ & * \\
\hline Ethyl heptanoate & 0.02 & 0.03 & $0.02 \pm 0.01$ & * \\
\hline Ethyl octanoate & 0.18 & 5.87 & $2.02 \pm 1.60$ & * \\
\hline Ethyl decanoate & 0.17 & 7.35 & $2.15 \pm 2.12$ & * \\
\hline Ethyl dodecanoate & 0.11 & 1.19 & $0.76 \pm 0.50$ & * \\
\hline \multicolumn{5}{|l|}{ Volatile phenols } \\
\hline Eugenol & 0.06 & 7.48 & $1.69 \pm 2.20$ & * \\
\hline Guaiacol & 0.11 & 0.59 & $0.09 \pm 0.18$ & * \\
\hline Isoeugenol & 0.13 & 0.36 & $0.18 \pm 0.12$ & n.s. \\
\hline trans-Anethole & 0.47 & 11.83 & $2.46 \pm 3.41$ & * \\
\hline \multicolumn{5}{|l|}{ Lactones } \\
\hline$\gamma$-Undecanolactone & 0.02 & 0.03 & $0.02 \pm 0.01$ & * \\
\hline
\end{tabular}


Table 3. Aroma descriptor, odour thresholds, odorant series and odour activity values

\begin{tabular}{|c|c|c|c|c|}
\hline Compound & Aroma descriptor $^{a}$ & $\begin{array}{l}\text { Odour threshold }{ }^{\mathrm{a}}(\mathrm{mg} / \\
\mathrm{L})\end{array}$ & $\begin{array}{l}\text { Odorant } \\
\text { series* }\end{array}$ & $O A V^{b}$ \\
\hline \multicolumn{5}{|l|}{ Terpenes } \\
\hline Linalool & Orange flowers,(36) floral, rose, aniseed $(39,50)$ & $0.05(50)$ & 1,3 & 33.61 \\
\hline$\alpha$-Terpineol & Lily, sweet, cake,(37) floral, iris, pine, lime tree(50) & $0.40(50)$ & $2,5,6$ & 0.70 \\
\hline Citronellol & Grapefruit, green lemon(50) & $0.018(50)$ & 1 & 5.56 \\
\hline Nerol & Orange flowers,(36) lime tree, floral, rose(50) & $0.4(50)$ & 2 & 0.23 \\
\hline Geraniol & $\begin{array}{l}\text { Orange flowers,(36)floral, rose,(50) floral sweet/fruity } \\
\text { (39) }\end{array}$ & $0.132(39,50)$ & 1,2 & 0.26 \\
\hline Menthol & Menthol(46) & - & 3 & - \\
\hline$\alpha$-Pinene & Mint, eucalyptus(50) & $1(50)$ & 3 & 0.03 \\
\hline Limonene & Citrus, fruity $(50)$ & $0.21(50)$ & 1 & 0.25 \\
\hline 1,8-Cineole & Mint, eucalyptus(50) & $0.0013(49)$ & 3 & 115.38 \\
\hline Thymol & Thyme, eucalyptus,(44) fruity(52) & $0.0017(52)$ & 1,3 & 143.53 \\
\hline \multicolumn{5}{|l|}{ Carbonyl compounds } \\
\hline Benzyl alcohol & Sweet, fruity(53) & $200(53)$ & 1,5 & 0.0 \\
\hline 2-Phenyl ethanol & Honey, spice, rose, lilac, floral(54) & $10(54)$ & 2 & 5.71 \\
\hline Benzaldehyde & $\begin{array}{l}\text { Roasted, almond,(37)mulberry, fruit,(51) } \\
\text { Smokey nutty(39) }\end{array}$ & $2(37,39)$ & 1,4 & 0.31 \\
\hline \multicolumn{5}{|l|}{$C_{13}$-norisoprenoids } \\
\hline$\alpha$-lonone & Floral (violet)(50) & $0.0026(50)$ & 2 & 3.54 \\
\hline$\beta$-lonone & Floral (violet) $(50)$ & $0.0045(50)$ & 2 & 4.95 \\
\hline$\beta$-Damascenone & $\begin{array}{l}\text { Tea, flowers,(36)stewed apples, apple } \\
\text { juice,(38) plum, raisins(39) }\end{array}$ & $0.00005(42)$ & $1,2,3$ & 301.65 \\
\hline \multicolumn{5}{|c|}{ Acetates and ethyl esters } \\
\hline Isoamyl acetate & Banana, mulberry, strawberry(38) & $0.03(39)$ & 1 & 20.71 \\
\hline Hexyl acetate & Grassy,(45) fruity, apple, pear(48) & $1.5(48)$ & 1,6 & 0.05 \\
\hline Phenyl ethyl acetate & Rose,(36,37) floral/honey(39) & $0.25(36,39,40)$ & 2 & 0.27 \\
\hline Ethyl propionate & Sweet, ethereal, fruity(47) & $1.8(47)$ & $1,5,6$ & 0.19 \\
\hline Ethyl butyrate & Strawberry,(38) pineapple,(41) kiwi(36) & $0.2(41)$ & 1 & 9.71 \\
\hline Ethyl hexanoate & $\begin{array}{l}\text { Ripe banana,(42) fruity, apple, floral, } \\
\text { violet, spice, anise,(48) candle-wax(41) }\end{array}$ & $0.005(42)$ & $1,2,3,6$ & 203.59 \\
\hline Ethyl heptanoate & Fruity, pineapple, sweet, banana, berry, cognac(47) & $0.22(47)$ & $1,5,6$ & 0.08 \\
\hline Ethyl octanoate & Fruity, pineapple, pear, floral,(48) candle-wax(41) & $0.005(48)$ & $1,2,6$ & 404.73 \\
\hline Ethyl decanoate & Chemical, soapy,(48) sweety, fruity, dry fruit(41) & $0.2(48)$ & $1,5,6$ & 10.73 \\
\hline $\begin{array}{l}\text { Ethyl dodecanoate } \\
\text { Volatile phenols }\end{array}$ & Sweet, waxy, floral, soapy ${ }^{41,}(48)$ & $0.8(48)$ & $2,5,6$ & 0.95 \\
\hline Eugenol & Clove $(36,50)$ & $0.006(50)$ & 3 & 282.48 \\
\hline Guaiacol & $\begin{array}{l}\text { Smoky, }(36,37,40) \text { plastic, medicinal,(38) } \\
\text { burning, sweet, phenolic }(40)\end{array}$ & $0.075(40)$ & $3,5,6$ & 1.17 \\
\hline Isoeugenol & Clove(36) & $0.006(43)$ & 3 & 29.95 \\
\hline $\begin{array}{l}\text { trans-Anethole } \\
\text { Lactones }\end{array}$ & Anise-like(45) & $0.073(45)$ & 3 & 33.68 \\
\hline $\begin{array}{l}\gamma \text {-Undecanolactone } \\
\text { Furanic aldehydes }\end{array}$ & Fruity(45) & - & 1 & - \\
\hline furfural & Bread, almond, sweet(51) & $150(53)$ & 4,5 & - \\
\hline $\begin{array}{l}\text { 5-Hydroxymethylfurfural } \\
\text { Phenolic aldehydes }\end{array}$ & Caramel tone(51) & - & 5 & \\
\hline Vanillin & Vanilla(51) & $0.06(53)$ & 3 & 10.7 \\
\hline
\end{tabular}

${ }^{a}$ Reference from which the aroma descriptor and the odour threshold value has been taken is given with superscript numbers. Genovese et al. (36); Franco et al. (37); Callejón et al. (38); Diéguez et al. (10); Rogerson et al. (39); Rocha et al. (40); Wechgama et al. (41); Selli et al. (42); Gómez-Míguez et al. (43); Zeller and Rychlik (32); Guillard et al. (44); Ong et al. (45); Cashion et al. (46); Zea et al. (47); Noguerol et al. (48); Fariña et al. (49); Burdock (50); Rodríguez-Bencomo et al. (51), Fan et al. (52), Etievant (53), Guth (54).

${ }^{\mathrm{b}} 1$, fruity; 2 , floral; 3, spice; 4, nutty; 5, sweet; 6, vegetal.

'Odour activity value is calculated by dividing concentration by odour threshold value of each compound. Compounds with OAV $\geq 1$ are in bold. 
can be found in other plants such as $R$. officinalis L. (22), M. piperita L. (23), Lippia citriodora (24) and M. fragrans (25). Another terpene found in a high proportion in the herb liqueurs analysed was menthol (2.17\%). This compound is not present in the volatile profile of grape marc distillates (19), so its concentration in herb liqueurs can only come from the traditional aromatic and medicinal plants used in the elaboration, mainly, M. piperita $L$ (26). Similar explanations can be applied to the presence of thymol in the samples analysed. This is the main compound present in T. vulgaris L. (27) and it also appears, but in low proportion, in other traditional aromatic and medicinal plants used [O. vulgare (28) and R. officinalis L. (29)]. The C13-norisoprenoids were present in low concentrations; however they are important for the global aroma due to their low threshold values.

Acetates and ethyl esters of volatile acids are the group of volatile compounds qualitatively more abundant in the composition of herb liqueurs. Their presence and concentration in the liqueur come from the distillate employed in the elaboration process. Ethyl butyrate $(2.49 \%)$, ethyl octanoate $(2.60 \%)$ and ethyl decanoate $(2.77 \%)$ were the major volatiles quantified from these families.

Among volatile the phenols, eugenol $(2.18 \%)$ and transanethole (3.16\%) also contribute to the global aroma of herb liqueurs. Both compounds are present in a relatively high concentration in some of the plants used in the maceration process (30-32).

Eugenol is one of the main compounds of cinnamon (33), but it can also appear in low concentrations in R. officinalis L. (34). According to previous research, this compound can be detected in low quantities $\left(\leq 0.44 \mathrm{mg} \mathrm{L}^{-1}\right)$ in grape marc distillates (19); however, the high concentration (i.e. $7.48 \mathrm{mg} \mathrm{L}^{-1}$ ) found in some of the liqueurs samples analysed suggests that this compound is extracted by the ethanol, during the maceration process, from cinnamon and/or $R$. officinalis L. trans-Anethole appears in high concentrations in some of the herb liqueurs analysed. It is probable that these beverages include $F$. vulgare among the plants used for the herb liqueur elaboration process, as trans-anethole is the main volatile compound detected in some subspecies of $F$. vulgare (35).

\section{Odour activity values and aromatic series}

In order to evaluate the most active odorants in herb liqueurs, the concentration of each volatile compound was correlated with its threshold value (as reported in the literature) and the corresponding results are showed in Table 3 . The majority (56\%) of the volatile compounds identified in the herb liqueurs analysed showed $O A V \geq 1$. All volatile phenols and $C_{13}$ norisoprenoids contribute directly to the global aroma of the herb liqueurs, increasing the spice and floral notes, respectively. Vanillin, with $\mathrm{OAV}=10.7$, also contributes to the spice intensity. Two important terpenes, linalool and citronellol, and a higher alcohol, 2-phenylethanol, showed high values of OAV, and these increase the floral notes of the herb liqueurs. All of the above-mentioned compounds come mainly from the plants employed in the elaboration of herb liqueurs. Other compounds, such as acetates and ethyl esters of volatile acids, showed high values of OAV, among them isoamyl acetate, ethyl butyrate, ethyl hexanoate, ethyl octanoate and ethyl decanoate. These volatiles are formed during alcoholic fermentation and distillation of grape pomace and contribute mainly with fruity notes. The rest of volatiles do not appear to contribute individually to wine aroma; with OAVs $<1$, however they can enhance some attributes by synergism effects with other active odorants.
To evaluate the global aroma of the herb liqueurs, all volatile compounds were grouped into six different classes (aromatic series), according to their similar odour descriptors. A compound with several descriptors may belong to different series. The total value in each series results from the sum of individual OAVs of the volatile compounds that are include in each class. Figure 1 shows the mean value of each aromatic series. Based in the synergic effects, compounds with OAV $<1$ were also included in the sum.

Results showed that 'spice' was the most important aromatic series to describe herb liqueurs. 'Fruity', 'floral' and 'vegetal' were also aromatic series with high influence in the overall aroma. However, 'sweet' and 'nutty' did not contribute directly to the global aroma of this kind of beverage.

Results must be completed with the corresponding profile resulting from the mean value of aroma descriptors given by a tasting panel. The aroma profile defined taking only into account the most active odorants (OAV) must be considered as a tentative.

\section{Principal component analysis}

In order to determine the influence of the different variables evaluated (phenols and volatiles) in the composition of herb liqueurs, a multivariate principal component analyses was carried out. A first PCA was performed on the concentration of the seven phenols determined in the 28 herb liqueurs analysed (Fig. 2). The first two principal components, PC1 and PC2, accounted for $75.37 \%$ of the total variance $(57.80 \%$ and $17.58 \%$, respectively).

The first component (PC1) was characterized by major concentration of vanillyl alcohol, acetovanillone, furfural and benzoic and vanillic acid. For the second component (PC2), HMF showed high and positive value, whereas, vanillin was negatively correlated. As a result of the high dispersion in the data obtained from the phenols determined in the samples studied, no statistical separation could be clearly observed. Most of the herb liqueurs analysed were located on the negative side of PC1 and were negatively influenced by the variables generated from the PCA

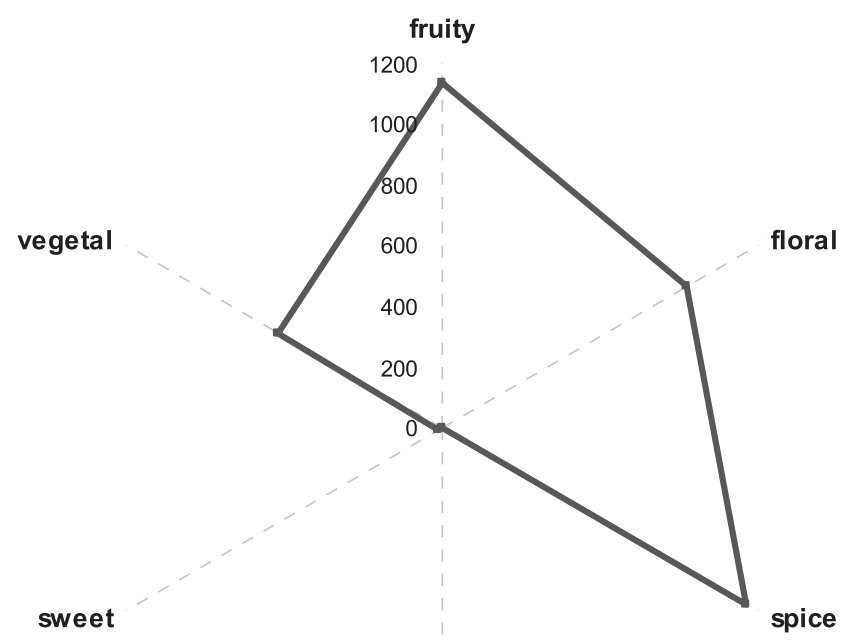

nutty

Figure 1. Mean value of aromatic series. 


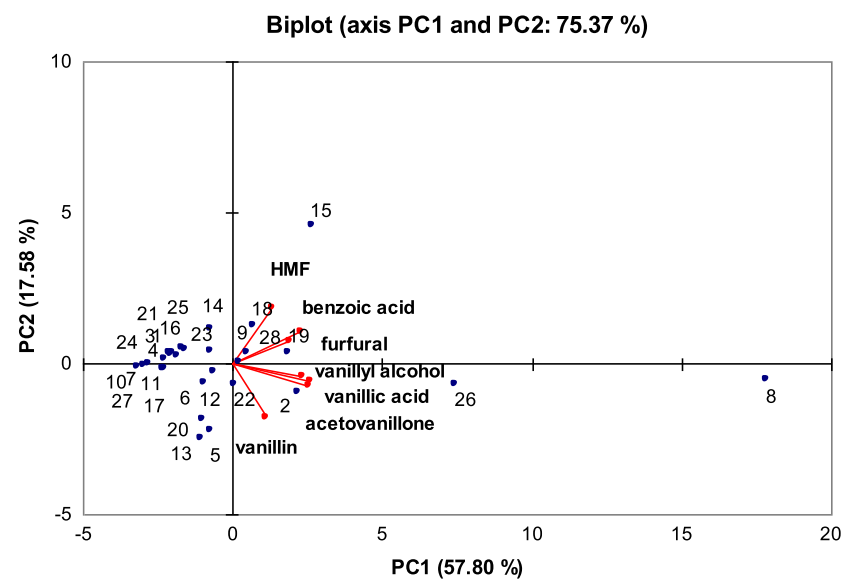

Figure 2. Principal component analysis (PCA) for herb liqueurs based on the phenolic compounds.

\section{Biplot (axis PC1 and PC2: $60.96 \%$ )}

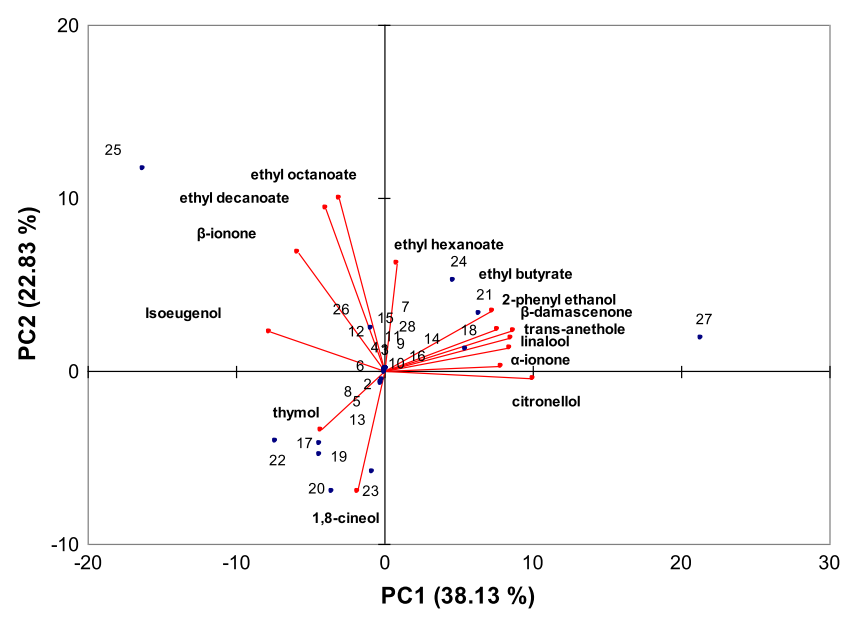

Figure 3. $P C A$ for herb liqueurs based on the impact odorants $(O A \vee \geq 1)$.

analysis. Only sample 15 , located at positive side of $P C 2$, was mainly characterized by a high content of HMF, and six samples $(2,8,9,18,19,26)$, located on the positive side of $\mathrm{PC} 1$, were characterized by vanillyl alcohol, acetovanillone, furfural and benzoic and vanillic acid.

A second PCA was performed on the concentration of impact odorants, volatiles with $\mathrm{OAV} \geq 1$, determined in the 28 herb liqueurs analysed (Fig. 3). Eighteen volatiles, from the 32 identified, were considered as impact odorants, and for this reason with a direct contribution to the aroma of the herb liqueurs. The first two principal components (PC1 and PC2) accounted for $60.96 \%$ of total variance (38.13 and $22.83 \%$, respectively). The first component (PC1) was positively correlated with citronellol, $\alpha$-ionona, linalool, $\beta$-damascenone and 2-phenyl ethanol and negatively correlated with isoeugenol. For the second principal component (PC2), all ethyl esters of volatile acids (ethyl hexanoate, ethyl octanoate, ethyl butyrate and ethyl decanoate) with $\beta$-ionone showed high and positive values, whereas 1,8-cineol and thymol contributed to the negative side of the same principal component. Three groups of herb liqueurs are shown in Fig. 3. A first group was characterized by thymol and 1,8-cineol. A second group correlated positively with the odorants located on the positive side of PC1 and, a third group, with low number of samples, defined by those odorants was sited on the positive side of PC2, ethyl esters and $\beta$ ionone.

\section{Conclusions}

This study shows the first approach to the chemical composition of herb liqueurs elaborated by maceration of traditional aromatic and medicinal plants in grape marc distillates. Twenty-eight different commercial brands were analysed by GC-FID, GC-MS and HPLCUV in order to identify the main volatile compounds and phenols that characterize the samples. All compounds showed significant differences in the concentration between the samples. Seven phenolic compounds were identified, the most abundant being those originated in the caramel employed in the liqueur elaboration (furfural and 5-hydroxymethylfurfural). Thirty-two volatile compounds, from eight chemical families, were identified and the corresponding OAVs were calculated. Eighteen volatiles showed $O A V \geq 1$, being considered as impact odorants and classified into six odorant series. Spice, fruity and floral were the series that most contributed to the aroma profile of the evaluated liqueurs. PCA analysis on phenol compounds (75.37\%) did not allow a clear separation of the samples owing to the high dispersion in the data obtained for the concentration of these compounds. However, a second PCA analysis on impact odorants $(60.96 \%)$ showed three different groups of herb liqueurs.

\section{Acknowledgments}

We are grateful to the Spanish Ministry of Economy and Competitiveness for the financial support of this work (project CTQ201571436-C2-1-R), which has partial financial support from the FEDER funds of the European Union. José Manuel Salgado was supported by the grant SFRH/BPD/84440/2012 from Fundação para a Ciência e Tecnologia - FCT, Portugal.

\section{References}

1. Bovo, B., Nardi, T., Fontana, F., Carlot, M., Giacomini, A., and Corich, V. (2012) Acidification of grape marc for alcoholic beverage production: Effects on indigenous microflora and aroma profile after distillation, Int. J. Food Microbiol. 152, 100-106.

2. Cortés, S., Rodríguez, N., Salgado, J. M., and Domínguez, J. M. (2010) The storage of grape marc: Limiting factor in the quality of the distillate, Food Control 21, 1545-1549.

3. Da Porto, C. (1998) Grappa and grape-spirit production, Crit. Rev. Biotechnol. 18, 13-24.

4. Da Porto, C. (2002) Volatile composition of 'grappa low wines' using different methods and conditions of storage on an industrial scale, Int. J. Food Sci. Technol. 37, 395-402.

5. Gerogiannaki-Christopoulou, M., Kyriakidis, N. V., Panagiotis, E., and Athanasopoulos, P. E. (2004) Effect of grape variety (Vitis vinifera L.) and grape pomace fermentation conditions on some volatile compounds of the produced grape pomace distillate, J. Int. Sci. Vigne Vin 38, 225-230.

6. Silva, M. L., and Malcata, F. X. (1998) Relationships between storage conditions of grape pomace and volatile composition of spirits obtained therefrom, Am. J. Enol. Vitic. 49, 56-64.

7. Apostopulou, A. A., Flouros, A. I., Demertzis, P. G., and Akrida-Demertzi, K. (2005) Differences in concentration of principal volatile constituents in traditional Greek distillates, Food Control 16, 157-164.

8. Cortés, S., Rodríguez, R., Salgado, J. M., and Domínguez, J. M. (2011) Comparative study between Italian and Spanish grape marc spirits in terms of major volatile compounds, Food Control 22, 673-680.

9. Silva, M. L., Macedo, A. C., and Malcata, F. X. (2000) Review: Steam distilled spirits from fermented grape pomace, Food Sci. Technol. Int. 6, 285-300. 
10. Diéguez, S., de la Peña, M. L., and Gómez, E. (2005) Volatile composition and sensory characters of commercial Galician orujo spirits, J. Agric. Food Chem. 53, 6759-6765.

11. Official Diary from Galicia (2012) Council Regulation 2012/1/16 on the definition, description and presentation of Geographical Indications Orujo, spirits herbs, herbal liqueur and coffee liqueur from Galicia, Galician Official Papers 10, 2516-2546.

12. Amico, V., Chillemi, R., Mangiafico, S., Spatafora, C., and Tringali, C (2008) Polyphenol-enriched fractions from Sicilian grape pomace HPLC-DAD analysis and antioxidant activity, Bioresour. Technol. 99, 5960-5966.

13. Casazza, A. A., Aliakbarian, B., Sannita, E., and Perego, P. (2012) Highpressure high-temperature extraction of phenolic compounds from grape skins, Int. J. Food Sci. Technol. 47, 399-405.

14. Pérez-Coello, M. S., Sanz, J., and Cabezudo, M. D. (1998) Gas chromatographic-mass spectrometric analysis of volatile compounds in oak wood used for ageing of wines and spirits, Chromatographia 47, 427-432.

15. Cai, Y., Luo, Q., Sun, M., and Corke, H. (2004) Antioxidant activity and phenolic compounds of 112 traditional Chinese medicinal plants associated with anticancer, Life Sci. 74, 2157-2184.

16. Cuvelier, M. E., Richard, H., and Berset, C. (1996) Antioxidative activity and phenolic composition of pilot-plant and commercial extracts of sage and rosemary, J. Am. Oil Chem. Soc. 73, 645-652.

17. Štěrbová, D., Matějı ček, D., Vlček, J., and Kubáň, V. (2004) Combined microwave-assisted isolation and solid-phase purification procedures prior to the chromatographic determination of phenolic compounds in plant materials, Anal. Chim. Acta 513, 435-444.

18. Mattila, P., and Kumpulainen, J. (2002) Determination of free and total phenolic acids in plant-derived foods by HPLC with diode-array detection, J. Agric. Food Chem. 50, 3660-3667.

19. Diéguez, S. C., de la Peña, M. L. G., and Gómez, E. F. (2003) Approaches to spirit aroma: Contribution of some aromatic compounds to the primary aroma in samples of Orujo spirits, J. Agric. Food Chem. 51, 7385-7390.

20. Msaada, K., Hosni, K., Taarit, M. B., Chahed, T., Kchouk, M. E., and Marzouk, B. (2007) Changes on essential oil composition of coriander (Coriandrum sativum L.) fruits during three stages of maturity, Food Chem. 102, 1131-1134.

21. Arey, J., Corchnoy, S. B., and Atkinson, R. (1991) Emission of linalool from Valencia orange blossoms and its observation in ambient air, Atmos. Environ. Pt A Gen. Top. 25, 1377-1381.

22. Gachkar, L., Yadegari, D., Rezaei, M. B., Taghizadeh, M., Astaneh, S. A and Rasooli, I. (2007) Chemical and biological characteristics of Cuminum cyminum and Rosmarinus officinalis essential oils, Food Chem. 102, 898-904.

23. Duarte, M. C. T., Figueira, G. M., Sartoratto, A., Rehder, V. L. G., and Delarmelina, C. (2005) Anti-Candida activity of Brazilian medicinal plants, J. Ethnopharmacol. 97, 305-311.

24. Pascual, M. E., Slowing, K., Carretero, E., Sánchez Mata, D., and Villar, A. (2001) Lippia: Traditional uses, chemistry and pharmacology: A review, J. Ethnopharmacol. 76, 201-214.

25. Piras, A., Rosa, A., Marongiu, B., Atzeri, A., Dessì, M. A., Falconieri, D., and Porcedda, S. (2012) Extraction and separation of volatile and fixed oils from seeds of Myristica fragrans by supercritical $\mathrm{CO}_{2}$ : Chemical composition and cytotoxic activity on Caco-2 cancer cells, J. Food Sci. 77, 448-453.

26. Iscan, G., Kirimer, N., Kürkcüoglu, M., Baser, H. C., and Demirci, F. (2002) Antimicrobial screening of Mentha piperita essential oils, J. Agric. Food Chem. 50, 3943-3946.

27. Giordani, R., Regli, P., Kaloustian, J., Mikail, C., Abou, L., and Portugal, H. (2004) Antifungal effect of various essential oils against Candida albicans. Potentiation of antifungal action of amphotericin B by essential oil from Thymus vulgaris, Phytother. Res. 18, 990-995.

28. Figiel, A., Szumny, A., Gutiérrez-Ortíz, A., and Carbonell-Barrachina, Á. A. (2010) Composition of oregano essential oil (Origanum vulgare) as affected by drying method, J. Food Eng. 98, 240-247.

29. Flamini, G., Cioni, P. L., Morelli, I., Macchia, M., and Ceccarini, L. (2002) Main agronomic-productive characteristics of two ecotypes of Rosmarinus officinalis L. and chemical composition of their essential oils, J. Agric. Food Chem. 50, 3512-3517.

30. Jurado, J. M., Ballesteros, O., Alcázar, A., Pablos, F., Martín, M. J., Vílchez, J. L., and Navalón, A. (2007) Characterization of aniseed-flavoured spirit drinks by headspace solid-phase microextraction gas

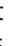

chromatography-mass spectrometry and chemometrics, Talanta 72 , 506-511.

31. Zeller, A., and Rychlik, M. (2006) Character impact odorants of fennel fruits and fennel tea, J. Agric. Food Chem. 54, 3686-3692.

32. Zeller, A., and Rychlik, M. (2007) Impact of estragole and other odorants on the flavour of anise and tarragon, Flav. Frag. J. 22, 105-113.

33. Kueffer, C., Schumacher, E., Fleischmann, K., Edwards, P. J., and Dietz, H. (2007) Strong below ground competition shapes tree regeneration in invasive Cinnamomum verum forests, J. Ecol. 95, 273-282.

34. Celiktas, O. Y., Kocabas, E. E., Bedir, E., Sukan, F. V., Ozek, T., and Baser, K. H. C. (2007) Antimicrobial activities of methanol extracts and essential oils of Rosmarinus officinalis, depending on location and seasonal variations, Food Chem. 100, 553-559.

35. Damjanović, B., Lepojević, Ž., Živković, V., and Tolić, A. (2005) Extraction of fennel (Foeniculum vulgare Mill.) seeds with supercritical $\mathrm{CO}_{2}$ : Comparison with hydrodistillation, Food Chem. 92, 143-149.

36. Genovese, A., Gambuti, A., Piombino, P., and Moio, L. (2007) Sensory properties and aroma compounds of sweet Fino Wine, Food Chem. 103, 1228-1236.

37. Franco, M., Peinado, R., Medina, M., and Moreno, J. (2004) Off-vine grape drying effect on volatile compounds and aromatic series in must from Pedro Ximénez grape variety, J. Agric. Food Chem. 52, 3905-3910.

38. Callejón, R., Morales, L., Troncoso, A., and Silva, A. (2008) Targeting key aromatic substances on the typical aroma of sherry vinegar, J. Agric. Food Chem. 56, 6631-6639.

39. Rogerson, F. S. S., and De Freitas, V. A. P. (2002) Fortification spirit, a contributor to the aroma complexity of port, J. Food Sci. 67, 1564-1569.

40. Rocha, S., Rodrigues, F., Coutinho, P., Delgadillo, I., and Coimbra, M. (2004) Volatile composition of Baga red wine Assessment of the identification of the would-be impact odorants, Anal. Chim. Acta 513, 257-262.

41. Wechgama, K., Laopaiboon, L., and Laopaiboon, P. (2008) Quantitative analysis of main volatile and other compounds in traditional distilled spirits from Thai Rice, Biotechnology 7, 718-724.

42. Selli, S., Canbas, A., Cabaroglu, T., Erten, H., and Günata, Z. (2006) Aroma components of cv. Muscat of Bornova wines and influence of skin contact treatment, Food Chem. 94, 319-326.

43. Gómez-Míguez, M., Cacho, J., Ferreira, V., Vicario, I., and Heredia, F. (2007) Volatile components of Zalema white wines, Food Chem. 100, 1464-1473.

44. Guillard, A., Le Quere, J., and Vendeuvre, J. (1997) Emerging research approaches benefit to the study of cooked cured ham flavor, Food Chem. 59, 567-572.

45. Ong, P., Acree, T., and Lavin, E. (1998) Characterization of volatiles in rambutan fruit (Nephelium lappaceum L.), J. Agric. Food Chem. 46, 611-615.

46. Cashion, L., Livermore, A., and Hummel, T. (2006) Odor suppression in binary mixtures, Biol. Psychol. 73, 288-297.

47. Zea, L., Moyano, L., Moreno, J., Cortés, B., and Medina, M. (2001) Discrimination of the aroma fraction of Sherry wines obtained by oxidative and biological ageing, Food Chem. 75, 79-84.

48. Noguerol-Pato, R., González-Barreiro, C., Cancho-Grande, B., and SimalGándara, J. (2009) Quantitative determination and characterisation of the main odorants of Mencía monovarietal red wines, Food Chem. $117,473-484$.

49. Fariña, L., Boido, E., Carraum, F., Versini, G., and Dellacassa, E. (2005) Terpene compounds as possible precursors of 1,8-cineole in red grapes and wines, J. Agric. Food Chem. 53, 1633-1636.

50. Burdock, G. A. (2010) Fenaroli's Handbook of Flavor Ingredients, 6th ed., Taylor and Francis, Boca Raton, FL.

51. Rodríguez-Bencomo, J. J., Ortega-Heras, M., Pérez-Magariño, S., González-Huerta, C., and González-San José, M. L. (2008) Importance of chip selection and elaboration process on the aromatic composition of finished wines, J. Agric. Food Chem. 56, 5102-5111.

52. Fan, G., Qiao, Y., Yao, X., Mo, D., Wang, K., and Pan, S. (2009) Free and bound volatile compounds in juice and peel of Jincheng oranges, Eur. Food Res. Technol. 229, 571-578.

53. Etievant, P. X. (1991) Wine, in Volatile compounds in Food and Beverages, (Maarse, H. Ed.) pp. 483-546, Marcel Dekker, New York.

54. Guth, H. (1997) Quantitation and sensory studies of character impact odorants of different white wine varieties, J. Agric. Food Chem. 45, 3027-3032. 